\title{
Forequarter amputation for malignant tumours of the upper extremity: Case report, techniques and indications
}

Vanessa Dimas BS, Jennifer Kargel BS, John Bauer MD, Peter Chang MD DMD

\begin{abstract}
V Dimas, J Kargel, J Bauer, P Chang. Forequarter amputation for malignant tumours of the upper extremity: Case report, techniques and indications. Can J Plast Surg 2007;15(2):83-85.

Forequarter (interscapulothoracic) amputation is a major ablative surgical procedure that was originally described to manage traumatic injuries of the upper extremity. Currently, it is most commonly used in the treatment of malignant tumours of the arm. With the advent of limb-sparing techniques, primary forequarter amputation is performed less frequently, but remains a powerful surgical option in managing malignant tumours of the upper extremity; therefore, surgeons should be familiar with this procedure. A classic case report of forequarter amputation, with emphasis on indications and surgical techniques, is presented.
\end{abstract}

Key Words: Forequarter amputation; Interscapulothoracic; Sarcoma; Shoulder girdle; Upper limb

\section{Une amputation interscapulothoracique en présence de tumeurs malignes de l'extrémité supérieure : Rapport de cas, techniques et indications}

\begin{abstract}
L'amputation interscapulothoracique est une intervention chirurgicale ablative importante qui a été décrite pour la première fois dans la prise en charge de lésions traumatiques de l'extrémité supérieure. Maintenant, elle est surtout utilisée pour le traitement de tumeurs malignes du bras. Grâce aux progrès des techniques d'épargne des membres, l'amputation interscapulothoracique est moins utilisée, mais elle demeure une puissante possibilité chirurgicale dans le traitement des tumeurs malignes de l'extrémité supérieure. Les chirurgiens devraient donc connaître cette intervention. Un cas classique d'amputation interscapulothoracique, axé sur les indications et les techniques chirurgicales, est présenté.
\end{abstract}

Corequarter (interscapulothoracic) amputation was first per- formed by Ralph Cuming in 1808. The first oncological forequarter amputation was reportedly performed by Dixie Crosby in 1836 for a case of osteosarcoma. In 1887, Paul Berger published a classic description of an anterior approach to forequarter amputation (1). The posterior approach was described by Littlewood in 1922 (1). Since then, numerous modified techniques, involving concomitant chest wall resection with reconstruction, have been described (2).

A forequarter amputation is a radical ablative surgical procedure that includes the entire upper extremity with its shoulder girdle (2). This procedure was originally described in the early 19th century to manage severe, traumatic injuries of the upper extremity $(3,4)$. Currently, the most frequent indications are the presence of malignant tumours of the arm, axilla, shoulder and scapula (2).

Limb-sparing surgery, preceded and followed by effective chemotherapy with or without radiation therapy, has replaced the radical surgical approach for treating limb sarcomas in most cases (5). Amputation of the affected extremity was considered for many years to be the standard of care for treating and curing patients with bone and soft tissue sarcomas of the limbs. Recent advances in limb-sparing techniques have reduced the number of major amputations performed for tumours of the upper extremity (1). The purpose of the present article is to familiarize surgeons with the indications for and surgical technique of this uncommon but valuable surgical procedure through presentation of a classic case report of

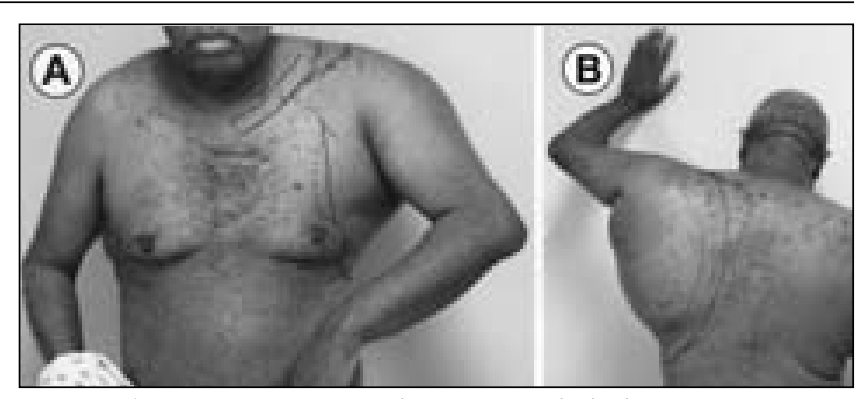

Figure 1) A Anterior view of the patient with the left upper extremity mass causing displacement of the arm at rest. B Posterior view of the patient with the left upper extremity mass limiting his range of motion

forequarter amputation for a malignant tumour of the upper extremity.

\section{CASE PRESENTATION}

A 57-year-old man was referred for a large, indurated and painful left upper extremity mass that had been increasing in size for five months (Figure 1). He had limited function of his arm due to mass effect and persistent, intractable pain. A complete metastatic evaluation, including magnetic resonance imaging and computed tomography, only revealed a large left upper extremity soft tissue mass surrounding the axillary vessels (Figure 2). Needle-core biopsy of the mass was suggestive of malignant fibrous histiocytoma (Figure 3). After

University of Texas Medical Branch, Galveston, Texas, USA

Correspondence: Dr Peter Chang, Cosmetic Surgical Institute, PO Box 1357, League City, Texas 77574, USA. Telephone 409-772-1255,

fax 409-772-1872, e-mail drpetechang@gmail.com 


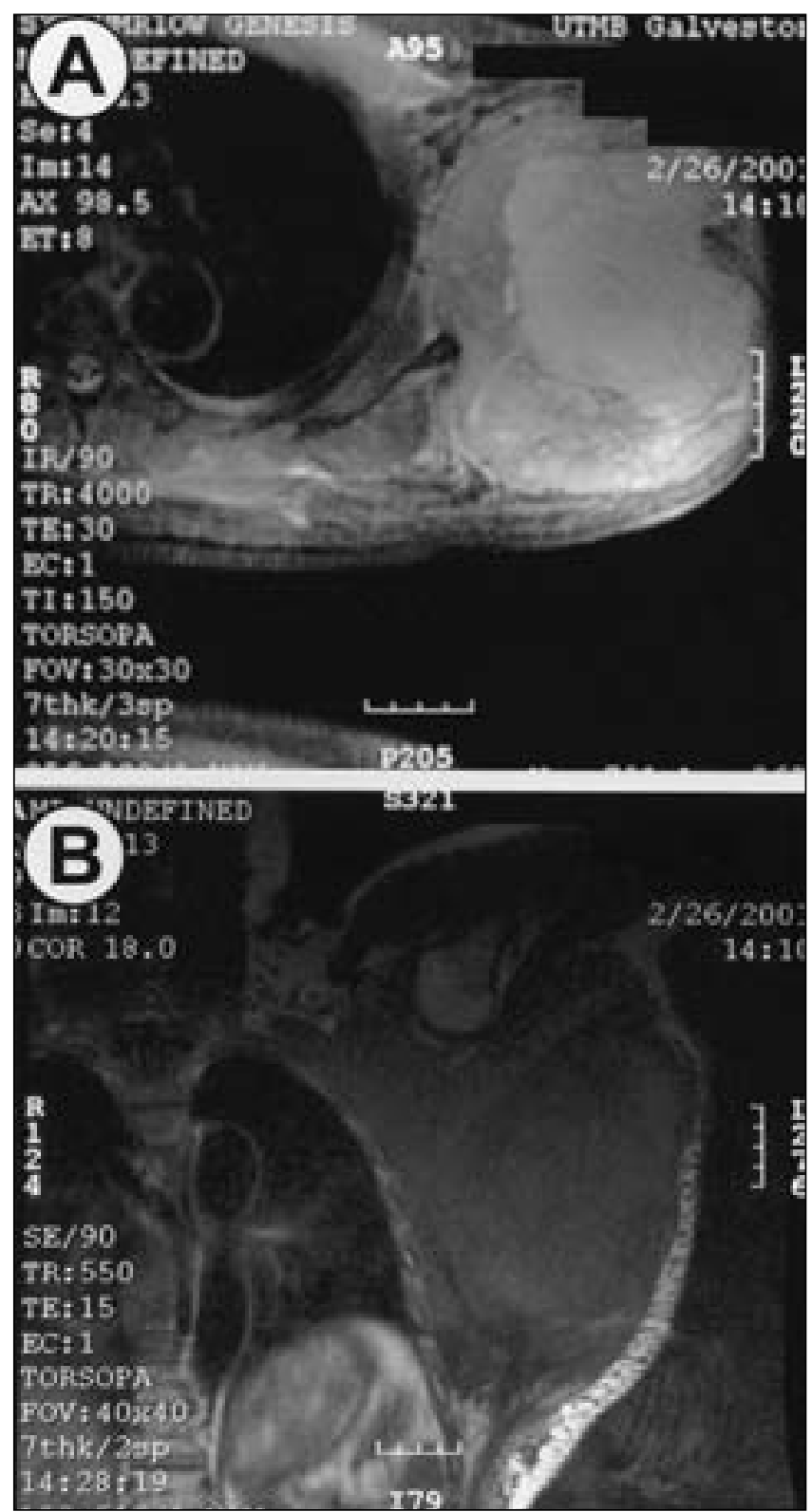

Figure 2) A Cross-sectional magnetic resonance image of the patient with a large left upper extremity mass. B Coronal magnetic resonance image of the same patient

a multidisciplinary discussion involving medical and radiation oncology, it was decided that the patient required surgical resection before radiation. He underwent forequarter amputation via an anterior approach (Figure 4). Surgical pathology confirmed the specimen to be malignant fibrous histiocytoma with negative nodes and clear margins. The patient's postoperative course, including six weeks of radiation, was uneventful. He experienced only occasional phantom limb pain, which is a common sequela of forequarter amputation.

\section{OPERATIVE TECHNIQUE}

The surgical technique for the present case of forequarter amputation was originally described by Berger in 1887 (1). The patient was placed in a right lateral decubitus position to expose the thorax, with the left upper extremity freely able to rotate. An anterior approach was used for this forequarter

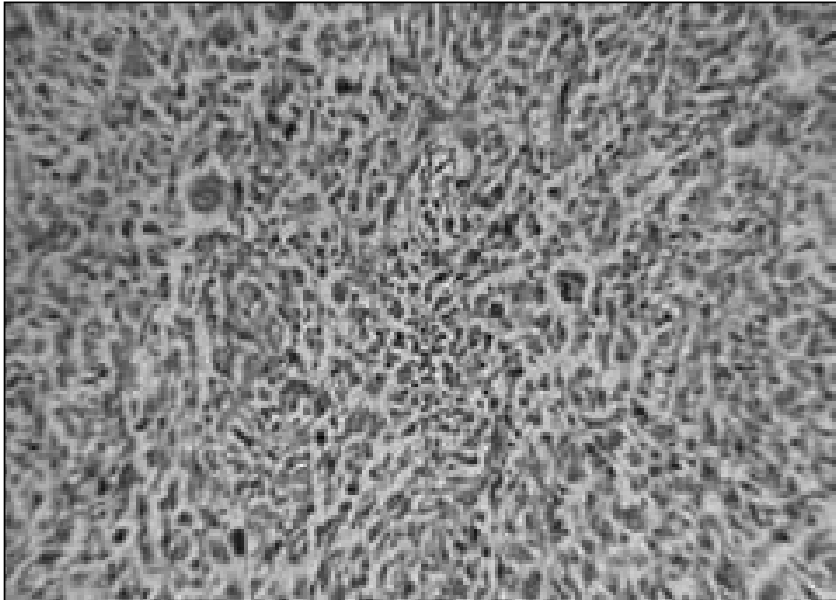

Figure 3) Photomicrograph of malignant fibrous histiocytoma (original magnification $\times 40$ )

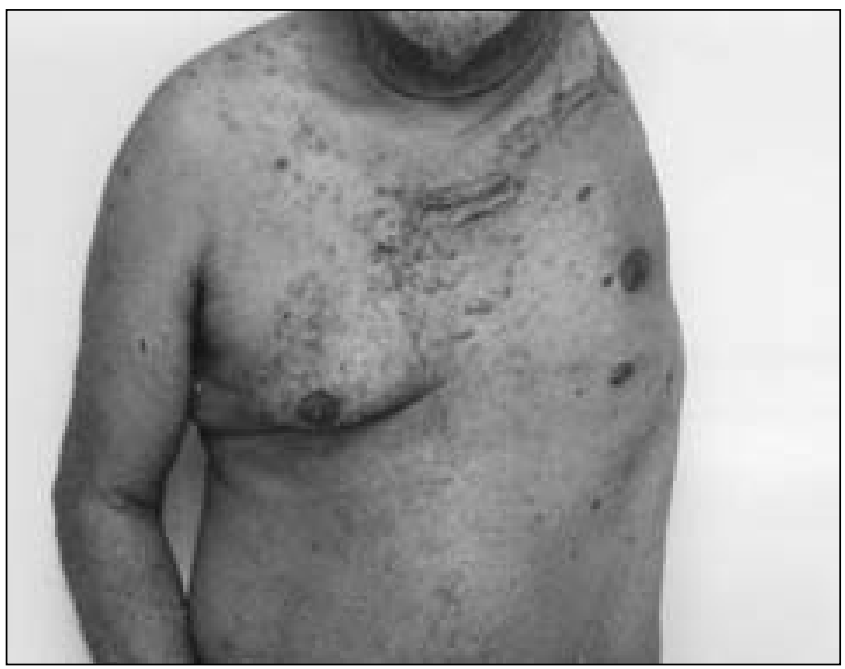

Figure 4) Anterior view of the postoperative forequarter amputation

amputation. A modified elliptical incision was made with the superior apex over the clavicle on one end and continued inferiolaterally. The inferior apex was made at the midaxillary line and continued posteriosuperiorly over the entire length of the scapula to join the superior apical incision. Soft tissue dissection was at the fascial level over the pectoralis major. The clavicle was exposed and divided at the proximal third; care was taken not to tear the underlying vein. The clavicle was carefully elevated to expose the subclavian artery, vein and brachial plexus. The subclavian artery was ligated and cut first, then the subclavian vein was tied and cut to prevent bleeding from the collateral blood supply of the shoulder. Branches of the brachial plexus were ligated and divided proximally (Figure 5). Next, the chest wall attachments of the pectoralis major and minor were divided. Posteriorly, fasciocutaneous skin flaps were developed and all periscapular muscles were released (Figure 6). This allowed the shoulder girdle to be freed and the whole extremity to fall away from the trunk. The anterior and posterior skin flaps were used to close the defect primarily. Any excess dog-ear skin was excised and closed primarily, and drains were placed. 


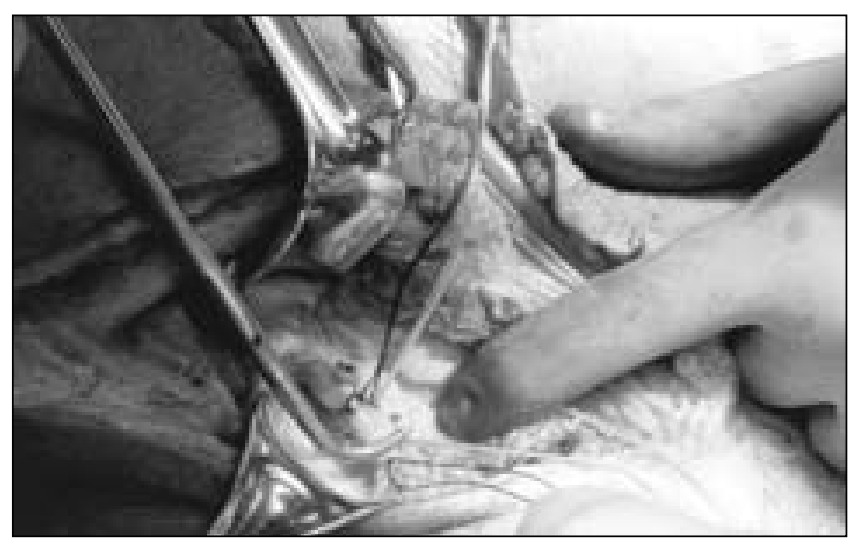

Figure 5) Intraoperative view of the divided clavicle, ligated subclavian artery and vein, and ligated brachial plexus

\section{DISCUSSION}

The goal of forequarter amputation (also known as shoulder girdle amputation) is to radically remove the bones and soft tissue of the upper extremities, including the scapula (1). Amputation of the affected extremity was considered, for many years, to be the standard of care for treating and curing patients with bone and soft tissue sarcomas of the limbs (5). Amputation surgery is not an abandoned idea today, but its application tends to be limited to cases of advanced disease that are unmanageable by a less radical approach or in patients with recurrent tumours after conservative treatment in whom limb salvage is not feasible anymore (6). Amputation has also been advocated as a palliative procedure for symptomatic, locally advanced disease that has already failed to respond to radiation therapy, chemotherapy and limited surgery (7). Forequarter amputation is usually performed when a limb-sparing operation is not possible, either following a severe injury to the upper limb or in managing primary soft tissue or bone tumours of the upper extremities. The indications include but are not limited to:

- There are no metastases to any other organs.

- Prognosis for treatment with chemotherapy or radiation therapy are considered extremely poor.

- Wide local excision is technically not feasible.

- The age and health of patient allows for a major surgical procedure, but not a series of reconstructive procedures.

\section{REFERENCES}

1. Yoak MB, Cocke WM Jr, Carey JP. Interscapulothoracic amputation. W V Med J 2001;97:148-50.

2. Levine EA, Warso MA, McCoy DM, Das Gupta TK. Forequarter amputation for soft tissue tumors. Am Surg 1994;60:367-70.

3. Bhagia SM, Elek EM, Grimer RJ, Carter SR, Tillman RM. Forequarter amputation for high-grade malignant tumours of the shoulder girdle. J Bone Joint Surg Br 1997;79:924-6.

4. Clark MA, Thomas JM. Major amputation for soft-tissue sarcoma. Br J Surg 2003;90:102-7.

5. Wittig JC, Bickels J, Kollender Y, Kellar-Graney KL, Meller I, Malawer MM. Palliative forequarter amputation for metastatic carcinoma to the shoulder girdle region: Indications, preoperative

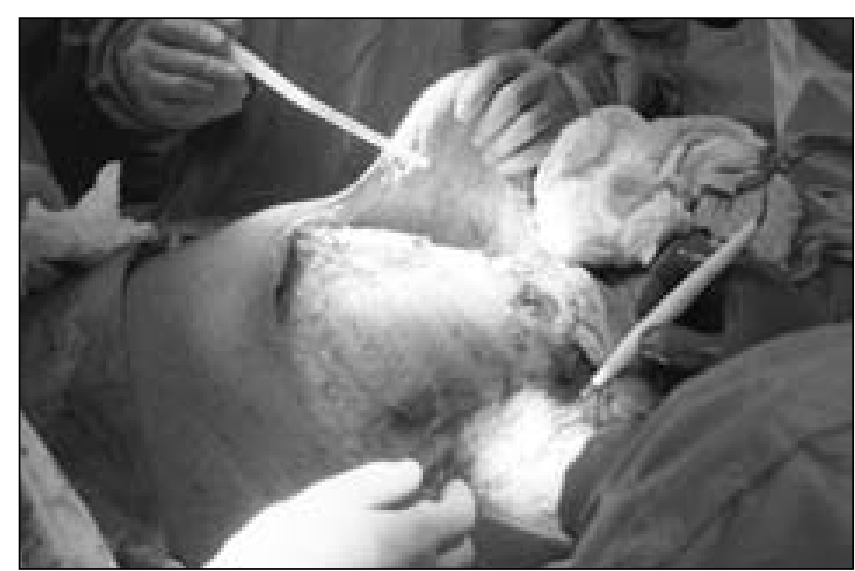

Figure 6) Development of fasciocutaneous skin flaps for primary closure

- The tumour has significantly impaired the functional status of the extremity to complete disuse or produces severe pain (8).

- The patient has an unresectable invasive tumour involving the shoulder joint or neurovascular bundle.

- There has been failure of conservative therapy (radiation/chemotherapy).

- The patient has had tumour-related complications such as bleeding, sepsis, limb dysfunction or severe lymphedema (5).

Despite disfiguring results, forequarter amputation is an effective procedure to cure and palliate tumours of the upper extremities (3). This procedure is usually well tolerated in carefully selected patients who are suffering intractable pain from a dysfunctional limb. Functional prosthetic rehabilitation is both difficult and expensive. Patients usually prefer a cosmetic arm and hand prosthesis (1).

\section{CONCLUSIONS}

Although forequarter amputation was initially described for the treatment of traumatic injuries, it is now more commonly used in managing malignant tumours of the upper extremity. Because this procedure is so deforming, most surgeons and patients do not select this treatment option. However, it is a relatively safe and reliable procedure for alleviating pain and improving quality of life for selected patients with unresectable tumours of the upper extremity.

evaluation, surgical technique, and results. J Surg Oncol 2001;77:105-14

6. Merimsky O, Kollender Y, Inbar M, Chaitchik S, Meller I.

Palliative major amputation and quality of life in cancer patients. Acta Oncol 1997;36:151-7.

7. Malawer MM, Buch RG, Thompson WE, Sugarbaker PH. Major amputations done with palliative intent in the treatment of local bony complications associated with advanced cancer. J Surg Oncol 1991;47:121-30.

8. Soucacos PN, Dailiana ZH, Beris AE, Xenakis TH, Malizos KN, Chrisovitsinos J. Major ablative procedures in orthopaedic surgery. Bull Hosp Jt Dis 1996;55:46-52. 